\title{
"Escribir una biografia es una experiencia investigadora fascinante": conversaciones con la historiadora María del Mar del Pozo Andrés
}

María del Mar del Pozo Andrés cursó sus estudios universitarios en la Facultad de Filosofía y Ciencias de la Educación de la Universidad Complutense de Madrid, donde también realizó su tesis doctoral, con la cual obtuvo el Premio Extraordinario de Doctorado y una Mención Honorífica en la modalidad de Tesis doctorales en los Premios Nacionales a la Investigación Educativa 1996. Toda su actividad profesional se ha desarrollado en la Universidad de Alcalá, de la que es Catedrática de Universidad del área de Teoría e Historia de la Educación. Ha participado también en masters y actividades docentes, como profesora visitante, en las Universidades de Rotterdam, Utrecht, Hamburgo, Lisboa, Salamanca, Complutense y Autónoma de Madrid. Ha ocupado el cargo de secretaria de la Sociedad Española de Historia de la Educación y fue miembro del Comité Ejecutivo de la International Standing Conference for the History of Education (ISCHE). Como investigadora ha trabajado sobre cuestiones de la historia de la educación española, particularmente el papel de la educación en la construcción de identidades nacionales en la enseñanza primaria y el movimento de la Escuela Nueva. Es autora de diversos artículos en revistas científicas españolas y internacionales y de livros, entre los cuales "Curriculum e identidad nacional. Regeneracionismo, nacionalismos y escuela publica" (Biblioteca Nueva, 2000). En el año passado, publicó la biografia de la maestra Justa Freire, planteada desde un nivel macro-micro, sobre la cual fue echa la entrevista que sigue abajo.

\section{Norberto Dallabrida}

Doutor em História Social pela Universidade de São Paulo. Realizou estágio pós-doutoral na Université Rene Descartes, Paris V. Professor Efetivo na Universidade do Estado de Santa Catarina. norberto.dallabrida@udesc.br

Entrevista concedida em: $17 / 12 / 2013$

\section{Para citar esta entrevista:}

ANDRÉS, María del Mar del Pozo. "Escribir una biografia es una experiencia investigadora fascinante": conversaciones con la historiadora María del Mar del Pozo Andrés. [Entrevista realizada em 17 de dezembro, 2013]. Revista Tempo e Argumento, Florianópolis, v. 6, n. 11, p. 467475, jan./abr. 2014. Entrevistador: Norberto Dallabrida.

\section{DOI: $10.5965 / 2175180306112014467$}

http://dx.doi.org/10.5965/2175180306112014467 
Tempo e Argumento - Usted acaba de publicar el libro "Justa Freire o la pasión de educar - Biografia de una maestra atrapada en la historia de España (1896-1965)" (Octaedro Editorial, 2013). Después de se dedicar a temas de la Historia de la Educación en España como el modelo de la escuela graduada y el movimiento de la Escuela Nueva, ?Por que usted escrebió un largo libro sobre una maestra?

María del Mar del Pozo Andrés - En realidad fue un proyecto que surgió casi por sí mismo, sin mucha reflexión previa por mi parte. En España hay ahora mucho interés por los diarios profesionales de maestros y maestras, y Justa Freire había escrito uno durante algunos años de su vida profesional. El proyecto inicial era transcribirlo y publicarlo con una pequeña introducción biográfica. Pero, a medida que transcribía el diario y me adentraba más en su vida, me interesó más hacer su biografía, no quería ser una mera copista. Más adelante, la familia de Justa Freire legó su archivo personal a la Fundación Ángel Llorca, y pude consultar todos sus papeles (más de 7.000 documentos). Muchos de ellos eran cartas y anotaciones personales. Poco a poco me fui enamorando del personaje y me ví atrapada por la experiencia biográfica. Desde luego, escribir una biografía es una experiencia investigadora fascinante y que no puede compararse con ninguna otra, por lo mucho que el autor o autora se implica emocionalmente. Además, se ponen en juego una cantidad enorme de resortes historiográficos, que se combinan para explicar la vida de una sola persona, pero que también es la vida de una generación, de los hombres y mujeres de un tiempo determinado. Es una experiencia magnífica para adquirir una comprensión mucho más amplia de la realidad histórica, al ver los acontecimientos históricos a través de los ojos de otra persona que los vivió, y al ponerse en lugar de esa persona. La historia desde esta perspectiva quizás se subjetiviza, pero también se enriquece y se humaniza. 
Tempo e Argumento - ¿Qué són los diarios profesionales de maestros y maestras? ¿Y por que, actualmente, en España, ha interese en estudialos?

María del Mar del Pozo Andrés - Los diarios profesionales de maestros y maestras son unos cuadernos en los que el docente escribía un resumen de su labor cotidiana (lo que había hecho cada día, los problemas encontrados, alguna anécdota,...). En las Escuelas Normales se recomendaba mucho a los alumnos que llevaran este diario para poder reflexionar sobre su práctica docente. Entraba dentro de lo que Antonio Viñao denominó "el imperio de lo escrito", es decir, el recurso a la documentación y registro de todas las actividades como forma de demostrar la eficacia profesional, especialmente en las nuevas escuelas que fueron las escuelas graduadas.

En los años treinta del siglo XX la mayoría de los maestros y maestras que escribían en las revistas pedagógicas y profesionales sobre su actividad dentro del aula, es decir, sobre sus experiencias como docentes y las innovaciones pedagógicas que habían introducido en sus escuelas, decían transcribir en esos artículos páginas de sus diarios, lo que nos da a entender que la práctica de la escritura diarística estaba bastante extendida entre los maestros y maestras integrados en el movimiento de la Escuela Nueva.

En España interesan en estos momentos los diarios profesionales porque son unas fuentes que - al igual que los cuadernos escolares, las memorias institucionales o las historias de vida - permite explorar más en profundidad el pensamiento de los profesores. También "están de moda" porque responden a las nuevas corrientes historiográficas que (como otros egodocumentos) permiten explorar las escrituras del yo y descubrir a los docentes como personas, además de desvelar algunos de los secreto de esa "caja negra" que es el aula escolar. 
Tempo e Argumento - Allá los diarios profesionales, que son fuentes mui interesantes y ricas, ¿Cuáles son los ego-documentos de Justa Freire que usted más usó para construir su biografia? Y por qué ella produzió y guardó documentos auto-biográficos?

María del Mar del Pozo Andrés - Contestaré primero a la segunda pregunta. Justa Freire conservó ego-documentos y documentos profesionales posiblemente por varias razones. En primer lugar, por imitar el ejemplo de su maestro Ángel Llorca, que también conservó un archivo muy abundante, archivo que le legó a ella, a Justa Freire, nombrándola "la heredera y conservadora de mis viejos papeles". En segundo lugar, porque, al igual que muchos maestros y maestras del movimiento de la Escuela Nueva, quería dejar constancia y testimonio de sus experiencias pedagógicas, quizás para que sirvieran de ejemplo y estímulo a las generaciones jóvenes de maestros y maestras. $\mathrm{Y}$, en tercer lugar, porque estos docentes eran muy conscientes del papel de la memoria en la construcción de la historia y quisieron conservar aquellos documentos que permitieran recordarles y escribir su propia historia. Sé que Justa Freire era muy consciente de los documentos que quería conservar y los que quería destruir; ella misma rompió y destruyó muchos de sus escritos, luego el acto de conservación no fue aleatorio y casual, fue el resultado de su decisión de dejar unos documentos que la sobrevivieran.

En cuanto a la primera pregunta, pues la verdad es que utilicé todos sus ego-documentos. Además del diario profesional que escribió desde el primer día al último que fue directora del Grupo escolar "Alfredo Calderón", realizó también un diario de los años de la Guerra Civil, con sus experiencias como organizadora de las Colonias Familiares de Educación y como supervisora y orientadora de las colonias escolares de Valencia. Cada vez que creía que iniciaba una etapa importante en su vida profesional, comenzaba a escribir un diario, y así lo hizo también en 1944, cuando fue contratada como profesora del Colegio Británico. Sin embargo, este diario duró solo unos meses, y esta brevedad es ya, de por sí, suficientemente significativa. También dejó notitas autobiográficas con los episodios y anécdotas que consideró más importantes de su vida profesional. $Y$ hay unos egodocumentos realmente interesantes, porque, en realidad, son escrituras infantiles, a través de las cuales se ve cómo Justa Freire contó un momento importante de su pasado, 
muchos años después, a los niños del Colegio Británico. En fin, que todos los egodocumentos de su archivo son interesantes, y revelan diferentes facetas de su yo.

Tempo e Argumento - Efectivamente, el archivo personal de Justa Freire es estupendo y ayudó mucho a escribir su biografía. Peró, para estructurar ese trabajo histórico entre el individual y el social, ¿cuales fueron los principales planteamientos teóricos que usted usó?

María del Mar del Pozo Andrés - En primer lugar, utilicé los planteamientos teóricos propios de la historia cultural, con sus ideas de retorno a la subjetividad y sus numerosos giros historiográficos (el de género, el visual, el sensorial, el emocional,... ). Por otra parte, tuve siempre presente el trabajar desde un nivel macro-micro, es decir, que intenté abordar la realidad histórica desde dos planos de análisis: el general o global (los grandes acontecimientos históricos, como la Guerra Civil; las grandes políticas educativas en la Segunda República o en el franquismo); y el particular y subjetivo de una persona concreta, Justa Freire, viendo cómo afectaban a su vida estos cambios globales. Así es que este trabajo se puede ver como un estudio de microhistoria, pero también como un panorama general de la historia de España visto a través de los ojos de una persona y de su círculo de relaciones. De ahí el subtítulo del libro, Biografía de una maestra atrapada en la historia de España.

Partí de la idea de que todos los sujetos que viven en un determinado momento histórico son protagonistas de la Historia (con mayúsculas) por igual, por ello debemos conocer sus historias particulares, que a manera de mosaico o puzzle nos ayudan a componer la Historia general de un país en un momento concreto. En cualquier caso, tampoco hice un esfuerzo especial por posicionarme en marcos teóricos consolidados, mi trabajo fue más el resultado de mi propia percepción de la labor del historiador en estos momentos concretos y de mi forma de abordar el oficio de historiador y la tarea de historiar. 
Tempo e Argumento - La "biografia coletiva" que usted hace de Justa Freire, trabaja mui bien la circulación y la apropiación de la Escuela Nueva en España entre los años entre del Post-Primera Guerra Mundial y la Guerra Civil Española. ¿Cuales son los factos historicos más interesantes sobre la Escuela Nueva que están conectados con Justa Freire?

María del Mar del Pozo Andrés - Justa Freire vivió el momento de máxima expansión de la Escuela Nueva en España, y formó parte de una generación de maestros y maestras que conoció a los protagonistas del movimiento, no sólo a través de sus libros, sino también en persona. Justa Freire viajó mucho por el extranjero, con becas ofrecidas por un organismo público, la Junta para Ampliación de Estudios e Investigaciones Científicas, o bien con sus propios ahorros. Visitó escuelas nuevas en Bélgica, Alemania, Suiza, Dinamarca y Suecia. Participó en el Curso de Vacaciones del Instituto Jean Jacques Rousseau y tuvo ocasión de conocer a pedagogos tan eminentes como Decroly o Piaget. Por lo tanto, aprendió las ideas de la Escuela Nueva escuchándolas directamente de los labios de sus promotores, e interiorizó las prácticas de la Escuela Nueva a partir de la observación de experiencias consideradas como innovadoras en esos años. Asistió también a dos congresos organizados por la Liga Internacional de Educación Nueva (los de Heidelberg, 1925 y Helsingör, 1929), que eran los espacios de encuentro de todos los educadores que se sentían atraídos e identificados con este movimiento.

Por otra parte, Justa Freire fue seleccionada en 1921 como maestra de un Grupo escolar, el "Cervantes", que fue considerado como una de las escuelas públicas españolas en las que se habían adoptado los ideales de la Nueva Educación. Por ella pasaron miles de maestros, con visitas cortas o estancias largas, de manera que fue una institución que actuó como filtro de las ideas renovadoras y ejemplo de cómo podían adaptarse a la realidad educativa española. Los maestros de este centro, liderados por su Director, Ángel Llorca, viajaron como equipo docente al extranjero, con el propósito de visitar escuelas nuevas y asistir al congreso de Heidelberg. A través de los diarios que todos ellos escribieron de la experiencia, es fácil constatar cómo se discutió sobre los que eran los pilares básicos del movimiento: el papel del niño como agente de su propia educación, la idea de actividad y su plasmación en la cotidianeidad escolar o la libertad del educando y 
sus posibles límites. De estas reflexiones fue surgiendo un modelo de Escuela Nueva adaptado a la escuela pública, modelo que, casi con seguridad, es el que inspiró los "Treinta puntos de la Escuela Nueva Pública" que elaboró Luzuriaga, y que se ajustaban como un guante a las características del Grupo escolar "Cervantes".

Tempo e Argumento - En varios capítulos del libro, usted trabaja mui bien la relación profesional y personal entre Justa Freire y Ángel Llorca, que empezó en el Grupo Escolar Cervantes. ¿Cuáles los principales aspectos de esta larga y profunda relación?

María del Mar del Pozo Andrés - En principio, era una relación profesional. Ángel Lorca era el director del Grupo escolar "Cervantes" y Justa Freire una de las maestras. Al encargarse de los aspectos más educativos del centro (comedor, entrevistas con los padres, veladas con las familias,...), tenían una comunicación constante. Justa Freire lo admiraba muchísimo, era su modelo, su ejemplo pedagógico, de él aprendió un estilo de enseñar y un estilo de dirección. Es posible que la relación estuviera a punto de convertirse en algo más personal en el año 1929; en el libro se recrea, a través de las cartas y los poemas que se conservan en el archivo de Justa Freire, una historia que quizás pudo ser pero que, desde luego, no cuajó.

A partir de ese momento, la relación profesional fue consolidándose en términos de igualdad. Ángel Llorca y Justa Freire, que habían comenzado siempre el maestro y la discípula, desarrollaron durante la Guerra Civil una experiencia educativa de colonias escolares, denominada Comunidades Familiares de Educación, dirigida por ambos en términos de igualdad, y sus relaciones en estos años tuvieron muchos momentos de roces y tensiones, debido, fundamentalmente, al fuerte carácter de Ángel Llorca. Pero, cuando acabó la Guerra Civil y Justa Freire fue encarcelada, D. Ángel le escribió cartas muy afectuosas, para que no decayera su espíritu y para que se mantuviera digna frente a la adversidad.

Como ya he dicho, Ángel Llorca dejó a Justa Freire en herencia su legado, su archivo, y ella consideró como su misión, casi sagrada, el preservar ese archivo y legarlo para las jóvenes 
generaciones. Por eso lo guardó en su sótano en unas circunstancias muy difíciles, cuando la posesión de esos documentos, en caso de que las autoridades hubieran registrado su casa, pudo haberle acarreado otra condena. Ángel Llorca ya había muerto y Justa le idealizó totalmente, se convirtió en su guía espiritual. En los años cincuenta, cuando el régimen franquista empezó una tímida apertura, Justa Freire concibió la idea de reeditar los libros de Ángel Llorca para que pudieran servir a los maestros jóvenes, y a ese empeño dedicó los últimos años de su vida.

Tempo e Argumento - ¿En vuestos estudios sobre escritos autobiográficos de maestros españoles y, en particular, en la biografia de Justa Freire, usted usa trabajos de la historiografía de la educación brasileña?

María del Mar del Pozo Andrés - A mí me gusta mucho el trabajo de los historiadores de la educación brasileños y siempre digo que el futuro de la Historia de la Educación está en Brasil, por la cantidad de universidades en las que se enseña esta disciplina, por el número de investigadores jóvenes que están realizando tesis de Máster y de Doctorado, por la fuerza de la Sociedad Brasileira de Historia de la Educación, por la pujanza de las revistas de investigación y por las múltiples posibilidades que los profesores brasileños tienen de viajar e intercambiar ideas con colegas de otros países. Es palpable, en todos los congresos internacionales, la inmensa presencia de los investigadores brasileños, frente al paulatino declinar del número de investigadores de otros países europeos, de Estados Unidos o de Australia.

En mi caso concreto, a mí me han influido mucho las investigaciones de Ana Chrystina Venancio Mignot. Sus trabajos sobre la maestra Armanda Álvaro Alberto, que tiene una vida paralela a la de Justa Freire, pues nació en 1892, fue una docente muy interesada en las ideas de la Escuela Nueva y relacionada con los círculos del Instituto J.J. Rousseau, también fue encarcelada durante un tiempo acusada de propagar ideas comunistas y, sobre todo, y al igual que Justa Freire, dedicó mucho tiempo a "archivar su propia vida", pudiéndose considerar esta experiencia de conservación de los "viejos papeles" — en 
expresión de la profesora Venancio Mignot inspirada en Philippe Artières - como base de un proyecto autobiográfico. Creo firmemente que esa misma idea estuvo presente en la conservación del archivo documental de Justa Freire y de otros maestros y maestras ligados a movimientos de renovación pedagógica en los años veinte. Y la primera que lo percibió claramente, y así lo publicó en el año 2000 en su contribución al libro Refúgios do eu, fue Ana Chrystina Venancio Mignot. 